\title{
Decarburization Kinetics of Fe-C-S Droplets with $\mathrm{H}_{2} \mathrm{O}$
}

\author{
Noel J. SIMENTO, Peter C. HAYES ${ }^{1)}$ and Hae-Geon LEE $^{2)}$
}

BHP-Long Products Division, P.O. Box 196B, Newcastle, N.S.W. 2300, Australia.

1) Department of Mining, Minerals and Materials Engineering, University of Queensland, Brisbane, Queensland 4072 , Australia. 2) Department of Materials Science and Metallurgical Engineering, Pohang University of Science and Technology, San 31, Hyoja-Dong, Nam-Ku, Pohang, 790-784, Korea.

(Received on January 5, 1998; accepted in final form on March 6, 1998)

\begin{abstract}
Decarburization of liquid Fe-C-S droplets with $\mathrm{H}_{2} \mathrm{O}$ vapour was investigated using the electromagnetic levitation technique. The results indicated that the decarburization of liquid iron droplets by $\mathrm{H}_{2} \mathrm{O}$ vapour can be adequately described by the mixed control of the gas phase mass transport and the dissociative chemisorption of $\mathrm{H}_{2} \mathrm{O}$ at the melt surface. The Steinberger-Treybal correlation equation was found to correctly represent the gas phase mass transfer in the present system geometry and experimental conditions. The rate of decarburization decreased significantly with increase in sulphur content in the melt, and this effect was quantitatively represented by the mixed control model. There exists a residual rate of decarburization at high sulphur contents in the melt. The extent of the residual rate observed can be interpreted as implying that, even at the melt surface of apparent saturation with sulphur, 8-9\% of the surface sites are still available for $\mathrm{H}_{2} \mathrm{O}$ molecules to react with carbon. The activation energy of dissociative chemisorption of $\mathrm{H}_{2} \mathrm{O}$ was $95 \mathrm{~kJ} \mathrm{~mol}^{-1}$.
\end{abstract}

KEY WORDS: decarburization; water vapour; mass transfer coefficient; levitation; kinetics; reaction rate.

\section{Introduction}

Achievement of high efficiencies of post combustion and heat transfer is of importance in the development of smelting reduction ironmaking processes. ${ }^{1-6)}$ There are two strategies which are commonly employed; namely, use of a deep foaming slag as energy transfer medium $^{1-3)}$ and, use of metal and slag droplets generated by high intensity of turbulence of the smelting bath. ${ }^{4-6)}$ In the latter case, a large number of droplets pass through the post-combusted gases at the top space of the bath, and hence heat is transferred to the droplets. The reaction characteristics of liquid droplets in the post combustion gases has a significant influence on the efficiency of smelting reduction processes. Of particular interest is the reactions of liquid $\mathrm{Fe}-\mathrm{C}-\mathrm{S}$ droplets with $\mathrm{H}_{2} \mathrm{O}$ in the gas phase, as smelting reduction processes may give off a significant amount of water vapour to the top space. ${ }^{7)}$

Decarburization with water vapour has not been extensively investigated. Consequently information on the chemical kinetic characteristics of the reaction is lacking. Early work ${ }^{8,9)}$ was conducted under conditions where decarburization was predominantly controlled by the gas phase mass transport. Fruehan et al. ${ }^{10)}$ investigated the decarburization reaction with carbon saturated iron melts using a crucible technique. They found that even with gas velocities as high as $13 \mathrm{~m} \mathrm{~s}^{-1}$, decarburization with water vapour encountered upto $10 \%$ resistance from the mass transfer in the gas phase. The dissociative chemisorption of the $\mathrm{H}_{2} \mathrm{O}$ molecule on the melt surface was deemed to be the slowest for the surface decarburization reaction.

In the present work, it was attempted to determine reaction rates and the rate limiting mechanism for the decarburization of levitating $\mathrm{Fe}-\mathrm{C}-\mathrm{S}$ melt droplets with water vapour. The effects of the partial pressure of $\mathrm{H}_{2} \mathrm{O}$, gas flowrate, melt compositions and temperature on the rate of decarburization were examined.

\section{Experimental}

The decarburization experiments were carried out by levitating liquid $\mathrm{Fe}-\mathrm{C}-\mathrm{S}$ droplets in a flowing gas stream in order to simulate metal drops flying in the top space of a smelting bath. Samples of iron alloys weighing $0.8 \mathrm{~g}$ were prepared from spectrographically pure reagents. A sample for reaction was placed in the levitation position within the coil (Fig. 1). The reaction vessel was flushed with argon gas for an appropriate period. The coil was then energised at the lowest power level which was then slowly raised to the pre-determined level so as to melt and support the sample. The levitating liquid drop was allowed to stabilize in its position and the temperature was brought to $1723 \mathrm{~K}$ by adjusting the power to the coil. The fourway stopcock and the generator timer were simultaneously switched to introduce pre-mixed and metered reaction gas for a prescribed duration. Control of the melt temperature was maintained during the reaction by manipulating the power to the coil. On completion of the reaction the generator shut down, 


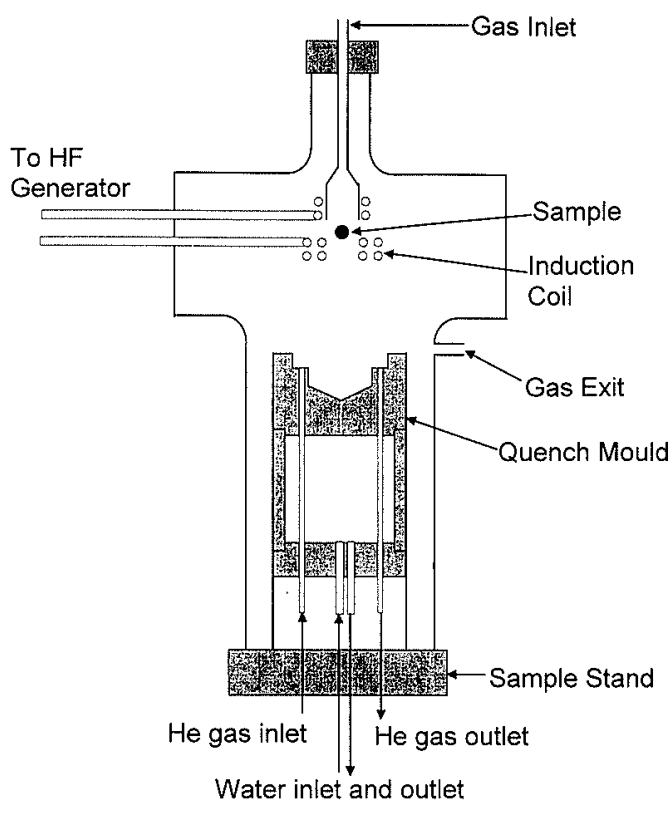

Fig. 1. Schematic diagram of experimental apparatus.

dropping the sample into a helium and water-cooled quench mould. The sample was removed from the mould and suitably stored. The quenched samples were then analyzed using combustion/IR spectrometry (CS444 Leco Analyser) and the rates of decarburization were obtained from the raw experimental data. In order to produce and maintain steam in its vapour form, a steam generator was used. Stoichiometric amounts of hydrogen and oxygen were metered into the burner contained in a glass reaction vessel. The gas mixture was ignited at the mouth of the burner by a heated platinum filament. The steam carrying conduits from the generator upto the delivery lance of the levitation reactor were kept heated using a resistance heating tape. The temperature of the gas mixture delivered to the levitation reactor was kept at $450 \mathrm{~K}$.

\section{Results and Discussion}

Decarburization rates obtained for all experimental conditions employed in this investigation are given in Table 1. The change in carbon concentration with time at different partial pressures of $\mathrm{H}_{2} \mathrm{O}$ and flowrates is shown in Fig. 2. It clearly indicates that the rate of decarburization of the melt is independent of the bulk carbon concentration until the melt composition reaches the liquidus at 1.24 mass $\%$ carbon at $1723 \mathrm{~K}^{12)}$ This linear relationship was also observed for all other experimental conditions, i.e., different sulphur concentrations and temperatures employed in this study. For the present conditions, therefore, it can be concluded that the liquid phase transport of carbon has no effect on the rate of decarburization with $\mathrm{H}_{2} \mathrm{O}$ vapour. This is in agreement with literature. ${ }^{10)}$ Similar observations have been reported for the decarburization with other oxidants including $\mathrm{CO}_{2}$ and $\mathrm{O}_{2} \cdot{ }^{13-18)}$ Once the liquidus was reached by decrease in carbon to 1.24 mass\%, levitation conditions were unstable and therefore the reaction was discontinued.
Table 1. Experimental results on decarburization using $\mathrm{H}_{2} \mathrm{O}$ vapour.

\begin{tabular}{|c|c|c|c|c|c|}
\hline \multicolumn{2}{|c|}{ Gas compositions (\%) } & \multirow{2}{*}{$\begin{array}{l}\text { Gas flowrate } \\
\left(\mathrm{m}^{3} \mathrm{~min}^{-1}\right)\end{array}$} & \multirow{2}{*}{$\begin{array}{c}\mathrm{T} \\
(\mathrm{K})\end{array}$} & \multirow{2}{*}{$\begin{array}{l}\text { Sulphur } \\
\text { (mass \%) }\end{array}$} & \multirow{2}{*}{$\begin{array}{c}-\mathrm{d} \% \mathrm{C} / \mathrm{dt} \\
\left(\text { mass } \% \mathrm{~s}^{-1}\right)\end{array}$} \\
\hline $\mathrm{H}_{2} \mathrm{O}$ & $\mathrm{N}_{2}$ & & & & \\
\hline 5 & 95 & 0.0147 & 1723 & $<0.0005$ & 0.0231 \\
\hline 10 & 90 & 0.0147 & 1723 & $<0.0005$ & 0.0495 \\
\hline 15 & 85 & 0.0147 & 1723 & $<0.0005$ & 0.0718 \\
\hline 20 & 80 & 0.0147 & 1723 & $<0.0005$ & 0.1000 \\
\hline 10 & 90 & 0.0073 & 1723 & $<0.0005$ & 0.0377 \\
\hline 10 & 90 & 0.0103 & 1723 & $<0.0005$ & 0.0417 \\
\hline 10 & 90 & 0.0175 & 1723 & $<0.0005$ & 0.0501 \\
\hline 10 & 90 & 0.0222 & 1723 & $<0.0005$ & 0.0569 \\
\hline 10 & 90 & 0.0147 & 1723 & 0.0025 & 0.0470 \\
\hline 10 & 90 & 0.0147 & 1723 & 0.0110 & 0.0401 \\
\hline 10 & 90 & 0.0147 & 1723 & 0.0550 & 0.0344 \\
\hline 10 & 90 & 0.0147 & 1723 & 0.1010 & 0.0285 \\
\hline 10 & 90 & 0.0147 & 1723 & 0.2700 & 0.0204 \\
\hline 10 & 90 & 0.0147 & 1693 & $<0.0005$ & 0.0492 \\
\hline 10 & 90 & 0.0147 & 1773 & $<0.0005$ & 0.0521 \\
\hline 10 & 90 & 0.0147 & 1823 & $<0.0005$ & 0.0536 \\
\hline
\end{tabular}

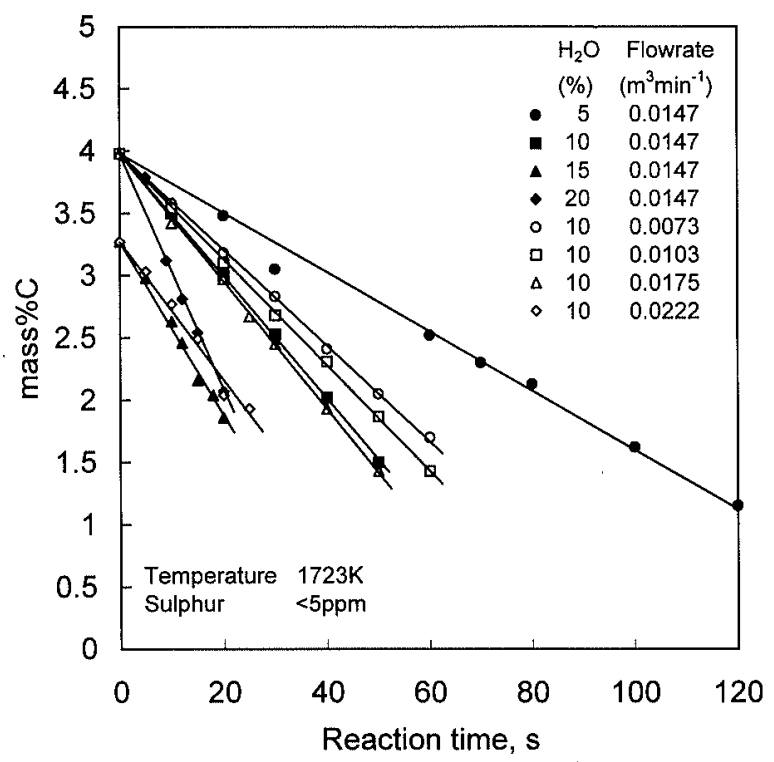

Fig. 2. Change of carbon content with reaction time at different $\mathrm{H}_{2} \mathrm{O}$ partial pressures.

\subsection{Gas Phase Transport}

Experiments were conducted in environments containing $\mathrm{H}_{2} \mathrm{O}$ in the range of 5 to $20 \%$ with $\mathrm{N}_{2}$ as diluent gas to investigate the effect of $\mathrm{H}_{2} \mathrm{O}$ partial pressure. The gas flowrate was maintained at $0.0147 \mathrm{~m}^{3} \mathrm{~min}^{-1}$ and the sulphur content in the melt was less than $5 \mathrm{ppm}$. The results are given in Fig. 3 which shows that the rate of decarburization increases linearly with the partial pressure of $\mathrm{H}_{2} \mathrm{O}$. The overall process of decarburization by $\mathrm{H}_{2} \mathrm{O}$ may be represented by the following reaction:

$$
\underline{\mathrm{C}}+\mathrm{H}_{2} \mathrm{O}(\mathrm{g})=\mathrm{CO}(\mathrm{g})+\mathrm{H}_{2}(\mathrm{~g})
$$

This reaction may be divided into a number of elementary steps:

1) Gas phase transport of $\mathrm{H}_{2} \mathrm{O}$

$$
\mathrm{H}_{2} \mathrm{O}^{b} \rightarrow \mathrm{H}_{2} \mathrm{O}^{\mathrm{i}}
$$




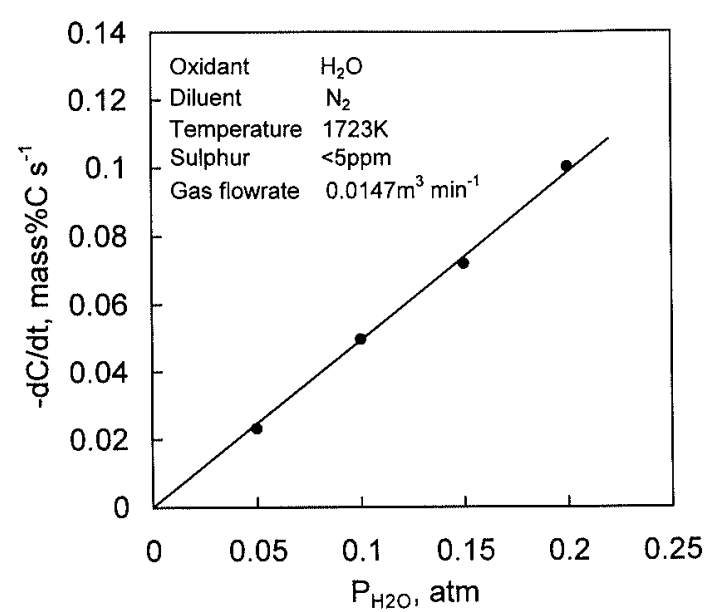

Fig. 3. Effect of $\mathrm{H}_{2} \mathrm{O}$ partial pressure on the rate of decarburization.

2) Dissociative chemisorption of $\mathrm{H}_{2} \mathrm{O}$ at the metal surface

$$
\mathrm{H}_{2} \mathrm{O}^{\mathrm{i}}+\mathrm{v} \rightarrow \mathrm{O}^{*}+\mathrm{H}_{2}^{\mathrm{i}}
$$

3) Decarburization reaction

$$
\mathrm{C}^{*}+\mathrm{O}^{*} \rightarrow \mathrm{CO}^{*}
$$

4) Desorption of $\mathrm{CO}^{*}$

$$
\mathrm{CO}^{*} \rightarrow \mathrm{CO}^{\mathrm{i}}+v
$$

5) Transport to the bulk gas phase

$$
\begin{aligned}
& \mathrm{CO}^{\mathrm{i}} \rightarrow \mathrm{CO}^{\mathrm{b}} \\
& \mathrm{H}_{2}^{\mathrm{i}} \rightarrow \mathrm{H}_{2}^{\mathrm{b}} \ldots
\end{aligned}
$$

where $v$ is a vacant site on the metal surface available for $\mathrm{H}_{2} \mathrm{O}$ adsorption and the superscript * represents the adsorbed state.

If the gas phase mass transport of $\mathrm{H}_{2} \mathrm{O}$ is the rate limiting step, Eq. (2) results in the following rate equation:

$$
-\frac{d(\% \mathrm{C})}{d t}=\frac{1200 A}{\rho_{\mathrm{m}} V} \frac{k_{\mathrm{g}}}{R T_{\mathrm{f}}} \ln \left(\frac{1+P_{\mathrm{H}_{2} \mathrm{O}}^{\mathrm{b}}}{1+P_{\mathrm{H}_{2} \mathrm{O}}^{\mathrm{i}}}\right) \quad \operatorname{mass}_{0 \mathrm{~s}^{-1}}
$$

where $A$ is the interfacial area, $\rho_{\mathrm{m}}$ is the molar density of the sample, $V$ is the volume of the sample, $k_{\mathrm{g}}$ is the gas phase mass transfer coefficient, $T_{\mathrm{f}}$ is the film temperature, and the superscripts $b$ and $i$ represent bulk and interfacial states, respectively.

Ignoring the partial pressure of $\mathrm{H}_{2} \mathrm{O}$ at the interface, Eq. (8) is reduced to

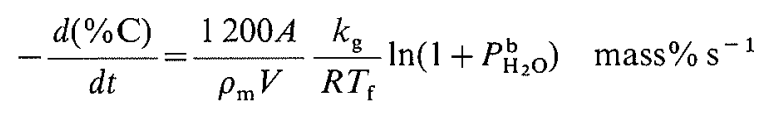

This equation predicts a linear relationship of the rate of decarburization with $\ln \left(1+P_{\mathrm{H}_{2} \mathrm{O}}^{\mathrm{O}}\right)$. Figure 4 proves that this is the case. In order to check the validity of the above, the theoretical prediction of decarburization rates under assumption that the rate is solely controlled by the gas phase mass transfer is also superimposed in the

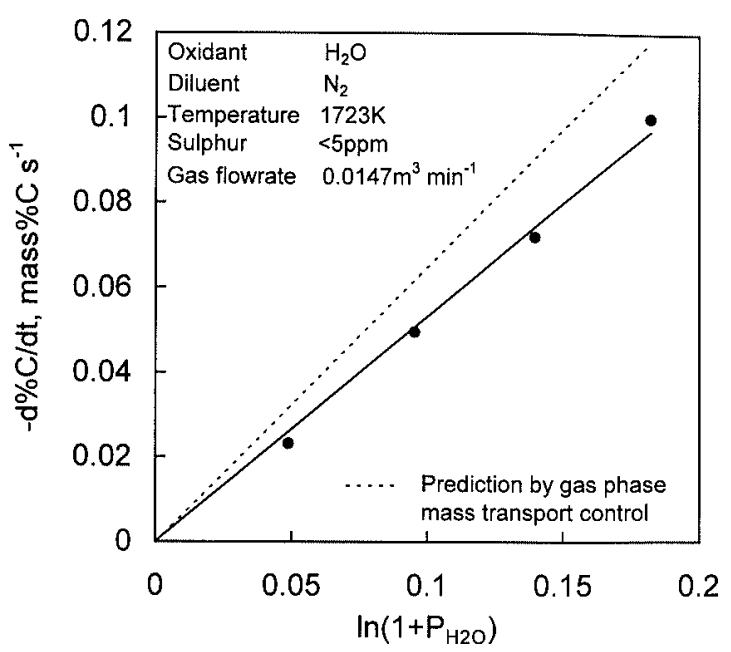

Fig. 4. Effect of $\mathrm{H}_{2} \mathrm{O}$ partial pressure on the rate of decarburization. Predictions by the gas phase mass transport control are included.

figure. For this the mass transfer coefficient in the gas phase, $k_{\mathrm{g}}$, can be calculated using Steinberger and Treybal's correlation equation ${ }^{19)}$ :

$$
\mathrm{Sh}=2+0.569\left(\mathrm{Gr}^{\prime} \mathrm{Sc}\right)^{0.25}+0.347 \mathrm{Re}^{0.62} \mathrm{Sc}^{0.31}
$$

In order to use the above equation, it is necessary to determine the physical properties of the gas mixture in the boundary layer. The determination of gas properties in levitation conditions is made difficult due to temperature and concentration gradients that are developed in the reaction system. For this investigation, the gas properties were determined at the film temperature $T_{f}$ using relationships documented by Bird et al. ${ }^{22)}$ and Perry et $a l^{23)}$ In the case of decarburization controlled by mass transport in the gas phase, the interfacial reaction is considered to be at equilibrium, and hence the gas phase at the interface will mainly consist of $\mathrm{N}_{2}, \mathrm{H}_{2}$ and $\mathrm{CO}$. On the other hand, the bulk gas comprises $\mathrm{N}_{2}$ and $\mathrm{H}_{2} \mathrm{O}$, and thus the gas compositions in the boundary layer should change along the radial direction. However, the change in the gas composition within the boundary layer is not large, since more than $80 \%$ in the gas is nitrogen for all the gas mixtures employed in the present study. Hence, the change in the physical properties with the change in gas composition in the boundary layer should be small. Hence a binary gas approximation consisting of nitrogen and steam is used to calculate the respective gas properties. This approximation has been justified by comparison of $k_{\mathrm{g}}$ 's calculated using Eq. (10) with two different gas compositions, namely, the bulk gas composition and the arithmetic mean of the bulk and interfacial compositions. The two values agree with each other within $3 \%$. For example, the value of $k_{\mathrm{g}}$ was found to be $0.34 \mathrm{~m} \mathrm{~s}^{-1}$ for the experimental conditions shown in Fig. 4 when the bulk gas composition was used in the calculation. If the arithmetic mean composition of the bulk and interface is used, this value is calculated to be $0.35 \mathrm{~m} \mathrm{~s}^{-1}$. Therefore, use of the bulk gas composition for calculation of the gas properties does not introduce unacceptable errors, in particular, considering the inherent uncertainties associated with Eq. (10) itself. The 
Table 2. Calculated gas properties at film temperature for experimental conditions.

\begin{tabular}{|l|c|c|c|c|c|}
\hline \multirow{2}{*}{$\begin{array}{l}\text { Gas } \\
\text { compositions }\end{array}$} & $\begin{array}{c}\text { Viscosity } \\
(\mu)\end{array}$ & $\begin{array}{c}\text { Diffusivity } \\
\left(D_{A B}\right)\end{array}$ & $\begin{array}{c}\text { Thermal } \\
\text { conductivity } \\
(\kappa)\end{array}$ & $\begin{array}{c}\text { Heat } \\
\text { capacity } \\
(\mathrm{Cp})\end{array}$ & $\begin{array}{c}\text { Density } \\
(\rho)\end{array}$ \\
\hline $510^{3} \mathrm{P}$ & $\times 10^{4} \mathrm{~m}^{2} \mathrm{~s}^{-1}$ & $\mathrm{JK}^{-1} \mathrm{~s}^{-1} \mathrm{~m}^{-1}$ & $\mathrm{kJkg}^{-1} \mathrm{~K}^{-1}$ & $\mathrm{kgm}^{-3}$ \\
\hline $10 \% \mathrm{H}_{2} \mathrm{O} \mathrm{O}-90 \% \mathrm{~N}_{2}$ & 0.41 & 2.23 & 0.067 & 1.23 & 0.31 \\
\hline $15 \% \mathrm{~N}_{2} \mathrm{O}-85 \% \mathrm{~N}_{2}$ & 0.41 & 2.23 & 0.069 & 1.35 & 0.30 \\
\hline $20 \% \mathrm{H}_{2} \mathrm{O}-80 \% \mathrm{~N}_{2}$ & 0.40 & 2.23 & 0.069 & 1.41 & 0.30 \\
\hline
\end{tabular}

gas properties computed using the bulk gas compositions are listed in Table $\mathbf{2}$ for the various gas mixtures used in this work.

It is noted in Fig. 4 that although the measured values of the rate show a linear relationship with $\ln \left(1+P_{\mathrm{H}_{2} \mathrm{O}}^{\mathrm{b}}\right)$, they are consistently lower than the values predicted under the assumption of gas phase mass transfer control. It is also noted in Fig. 3 that the same measured values gave rise to an equally valid linear relationship with $P_{\mathrm{H}_{2}}^{\mathrm{b}}$. This is because $P_{\mathrm{H}_{2} \mathrm{O}}^{\mathrm{b}} \approx \ln \left(1+P_{\mathrm{H}_{2} \mathrm{O}}^{\mathrm{b}}\right)$ at low $P_{\mathrm{H}_{2} \mathrm{O}}^{\mathrm{b}}$. Therefore, these apparent first order relationships are not sufficient, on their own, to distinguish between rates limited by gas phase mass transport and by interfacial chemical kinetics.

In order to test for the effect of gas phase mass transport, the rates of decarburization were obtained at different gas flowrates ranging from 0.0075 to 0.0225 $\mathrm{m}^{3} \mathrm{~min}^{-1}$. This range represents an exit gas velocity from 1.10 to $3.32 \mathrm{~m} \mathrm{~s}^{-1}$. The partial pressure of steam was maintained at $0.1 \mathrm{~atm}$ with the diluent gas of nitrogen and the sulphur content of the melt was kept below $5 \mathrm{ppm}$. As shown in Fig. 5, the decarburization rate increases with increasing gas flowrate. Since the increase in the gas flowrate increases the gas phase mass transfer coefficient, this observation is characteristic of a process whose rate is affected by the gas phase mass transfer. It is seen in Eq. (10) that the gas flowrate influences the third term in the right hand side of the equation, which reflects the effect of the forced convection. Included in Fig. 5 are the rates of decarburization predicted using Eq. (10) under assumption that the rate is controlled solely by the gas phase transport. It is seen from the figure that the predicted rate is consistently higher than the measured one over the range of flowrate examined, but gradually approaches the measured one, as the flowrate decreases.

Earlier work ${ }^{10}$ ) has shown that the transport of $\mathrm{CO}$ from the reaction interface to the bulk gas has no effect on the rate of decarburization even at the $\mathrm{CO}$ partial pressure of $0.9 \mathrm{~atm}$. This was also verified in the concurrent work by the authors ${ }^{18)}$ with $\mathrm{CO}$ and $\mathrm{CO}_{2}$. Transport properties of $\mathrm{H}_{2}$ are much larger than other gases, ${ }^{20)}$ and hence the transport of $\mathrm{H}_{2}$ in the gas phase should not exert resistance to the decarburization.

In summary, it can be concluded from observations described above that the gas phase mass transport of $\mathrm{H}_{2} \mathrm{O}$ vapour plays a main role in determining the rate

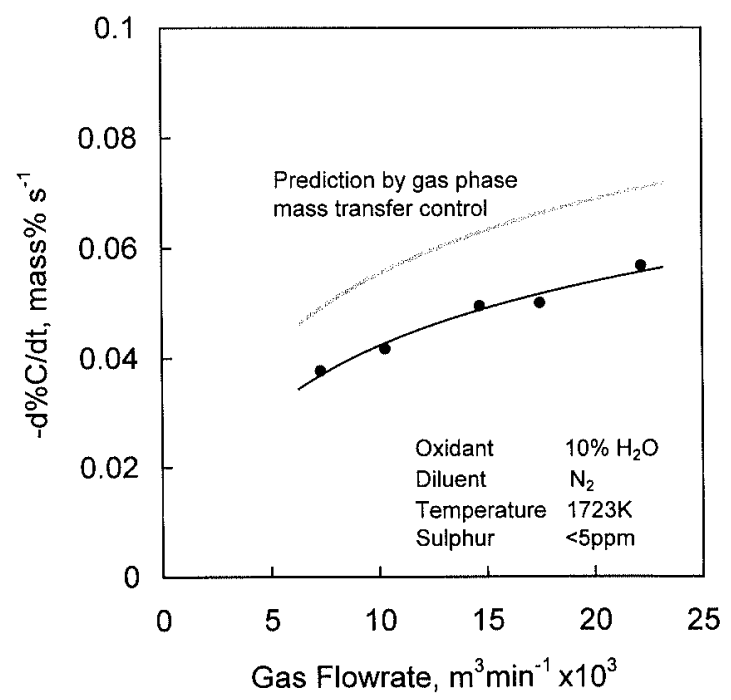

Fig. 5. Effect of gas flowrate on the rate of decarburization with $\mathrm{H}_{2} \mathrm{O}$. Predictions by the gas phase mass transport control are included.

of decarburization under the present experimental conditions.

\subsection{Interfacial Reactions}

Earlier work ${ }^{10)}$ have shown that, of three interfacial reactions represented by Eqs. (3) to (5), the latter two reactions are not considered to be rate controlling. This view is further supported by the report ${ }^{14)}$ on decarburization with $\mathrm{CO}_{2}$ in that these two reactions were found not rate limiting for the interfacial reaction. From Eq. (3), therefore, the rate of decarburization can be represented by the following equation:

$$
-\frac{d(\% \mathrm{C})}{d t}=\frac{1200 A}{\rho_{\mathrm{m}} V} k_{\mathrm{c}} C_{\mathrm{v}} P_{\mathrm{H}_{2} \mathrm{O}}^{\mathrm{i}} \quad{\text { mass } \% \mathrm{~s}^{-1}}^{-1}
$$

where $k_{\mathrm{c}}$ is the rate constant of the forward reaction of Eq. (3), and $C_{\mathrm{v}}$ is the fractional surface site which is available for $\mathrm{H}_{2} \mathrm{O}$ adsorption. If the decarburization is solely controlled by the dissociative chemisorption of $\mathrm{H}_{2} \mathrm{O}$ at the melt surface, $P_{\mathrm{H}_{2} \mathrm{O}}^{\mathrm{i}}$ in Eq. (11) would be almost the same as the bulk pressure of $\mathrm{H}_{2} \mathrm{O}, P_{\mathrm{H}_{2} \mathrm{O}}^{\mathrm{b}}$. However, it was discussed earlier that the resistance from the gas phase transport is not negligible. In order to describe the decarburization kinetics with $\mathrm{H}_{2} \mathrm{O}$ in a proper manner, therefore, it is necessary to consider both the gas phase mass transport and interfacial chemical reaction. Thus, 
a mixed control model can be derived by combining Eqs. (8) and (11). Combination of these two equations by eliminating $P_{\mathrm{H}_{2} \mathrm{O}}^{\mathrm{i}}$ yields

$$
-\frac{d(\% \mathrm{C})}{d t}=\frac{1200 \mathrm{~A}}{\rho_{\mathrm{m}} V}\left(\frac{k_{\mathrm{g}}^{\circ} k_{\mathrm{c}} C_{\mathrm{v}}}{k_{\mathrm{g}}^{\circ}+k_{\mathrm{c}} C_{\mathrm{v}}}\right) \ln \left(1+P_{\mathrm{H}_{2} \mathrm{O}}^{\mathrm{b}}\right)
$$

where $k_{\mathrm{g}}^{\circ}=k_{\mathrm{g}} /\left(R T_{\mathrm{f}}\right)$.

Equation (12) thus represents the rate of decarburization under the mixed control by both the gas phase mass transfer and the dissociative chemisorption of $\mathrm{H}_{2} \mathrm{O}$. This equation predicts a linear relationship between the rate of decarburization and $\ln \left(1+P_{\mathrm{H}_{2} \mathrm{O}}^{\mathrm{b}}\right)$ for a given melt composition. Since sulphur is surface active in liquid iron, its presence in the melt will significantly reduce the value of $C_{v}$ in the above equation. If sulphur is the only element which blocks sites for $\mathrm{H}_{2} \mathrm{O}$ adsorption, $C_{v}$ can be represented by Eq. (13):

$$
C_{\mathrm{v}}=1-\theta_{\mathrm{S}}
$$

where $\theta_{\mathrm{S}}$ is the fractional surface sites occupied by sulphur.

There may also exist some surface sites which cannot be blocked by sulphur: the reason for this being either stirring effect of the melt, the penetration of $\mathrm{H}_{2} \mathrm{O}$ molecules through the chemisorbed sulphur layer when arrived at a particular orientation, residual disorder, misfit in the chemisorbed surface layer or hydrodynamic effects of the melt. If we accept one of the above possibilities and adopt the Langmuir isotherm for sulphur adsorption,

$$
K_{\mathrm{S}}=\frac{\theta_{\mathrm{S}}}{\left(1-\theta_{\mathrm{S}}-\theta_{\mathrm{U}}\right) a_{\mathrm{S}}}
$$

where $K_{\mathrm{S}}$ is the adsorption coefficient of sulphur, $\theta_{\mathrm{U}}$ is the fractional surface sites which are not available for sulphur adsorption, and $a_{\mathrm{S}}$ is the sulphur activity in the bulk metal.

Combination of Eqs. (13) and (14) yields

$$
C_{\mathrm{v}}=\frac{1+\theta_{\mathrm{U}} K_{\mathrm{S}} a_{\mathrm{S}}}{1+K_{\mathrm{S}} a_{\mathrm{S}}}
$$

Effect of sulphur on decarburization can thus be adequately represented by Eq. (12) together with Eq. (15). Figure 6 shows the experimental results of decarburization with $\mathrm{H}_{2} \mathrm{O}$ vapour at different sulphur contents in the melt. It is clearly seen that the rate decreases with increase in the sulphur content. Superimposed in Fig. 6 are the rates of decarburization calculated by curve fitting using Eq. (12). The value of $k_{\mathrm{g}}^{\circ}$ used in the calculation is $4 \mathrm{~mol} \mathrm{~m}^{-2} \mathrm{~s}^{-1}$ which was obtained from the earlier calculation using the Steinberger-Treybal equation, Eq. (10). The value of $K_{\mathrm{S}}$ was determined to be 200 by a separate study for $\mathrm{CO}_{2}$ decarburization, ${ }^{21)}$ which employed the same experimental setup as the present study. However, Belton ${ }^{7)}$ has recommended 450 for $K_{\mathrm{S}}$ at $1450^{\circ} \mathrm{C}$. The reason for this discrepancy is not immediately clear. Nevertheless, the values of $k_{\mathrm{C}}$ and $\theta_{\mathrm{U}}$ were determined by regression for the best fitting of Eq. (12) to the present results. These were found to be

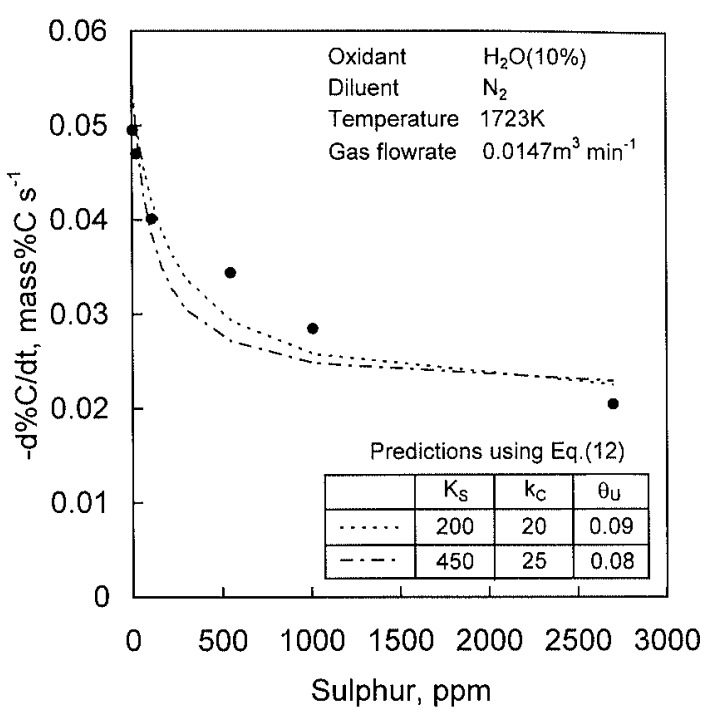

Fig. 6. Effect of sulphur on the rate of decarburization with $\mathrm{H}_{2} \mathrm{O}$. Predictions by the mixed control model are also included.

$20 \mathrm{~mol} \mathrm{~m}^{-2} \mathrm{~s}^{-1}$ and 0.09 , respectively, with $K_{\mathrm{S}}=200$, and $25 \mathrm{~mol} \mathrm{~m}^{-2} \mathrm{~s}^{-1}$ and 0.08 with $K_{\mathrm{S}}=450$. The reliability of these calculated values is dependent on the accuracy of the values of $k_{\mathrm{g}}^{\circ}$ and $K_{\mathrm{S}}$ chosen. As seen above, however, $k_{\mathrm{C}}$ and $\theta_{\mathrm{U}}$ have been found not to sensitively vary with $K_{\mathrm{S}}$. Sasaki et $a{ }^{111}{ }^{11}$ has reported the value of $35 \mathrm{~mol}$ $\mathrm{m}^{-2} \mathrm{~s}^{-1}( \pm 35 \%)$ for the rate constant $\left(k_{\mathrm{C}}\right)$ of the dissociative chemisorption of $\mathrm{H}_{2} \mathrm{O}$ at $1723 \mathrm{~K}$. Fruehan et al. ${ }^{10)}$ has reported a higher value of $55 \mathrm{~mol} \mathrm{~m}^{-2} \mathrm{~s}^{-1}$. The reason for the discrepancy between the investigators is not immediately clear. It may be the difference in the system geometry. Incoming oxidants are not likely to be uniformly distributed over the entire interfacial area. For the levitation geometry like the one employed in the present work there may exist a significant variation of the gas dynamics around the levitating drop. For the crucible method employed by the other investigators, ${ }^{10,11)}$ the distribution of oxidants may vary to a significant extent across the radial direction in the crucible. Therefore, the use of the geometric area for the interfacial reaction area in the calculation of the rate constant may result in a value which is geometry-specific.

The value of $0.08-0.09$ for $\theta_{U}$ obtained in the above can be interpreted as implying that, even at the melt surface of apparent saturation with sulphur, 8-9\% of the surface sites are still available for $\mathrm{H}_{2} \mathrm{O}$ molecules to react with carbon. This gives rise to a residual rate of decarburization at high sulfur contents in the melt. In the concurrent work by the authors ${ }^{21)}$ with $\mathrm{CO}_{2}$, it was found that $\theta_{\mathrm{U}}$ is 0.014 . Sain and Belton ${ }^{14)}$ also reported the value of 0.014 from the results of $\mathrm{CO}_{2}$ decarburization by crucible method. But Lee and Rao ${ }^{17)}$ reported the values of 0.085 from $\mathrm{CO}_{2}$ decarburization by levitation technique. Therefore the residual rate of decarburization appears to be influenced by a number of factors including the system geometry, oxidising species, and the hydrodynamics of the melt.

In summary, decarburization of liquid iron droplets by $\mathrm{H}_{2} \mathrm{O}$ vapour can be adequately described by the mixed control of the gas phase mass transport and dissociative 


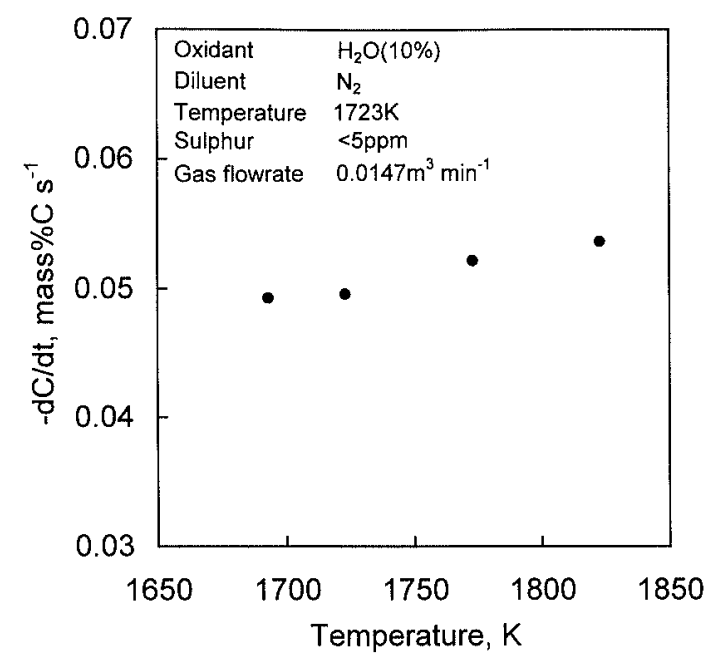

Fig. 7. Effect of temperature on the rate of decarburization with $\mathrm{H}_{2} \mathrm{O}$.

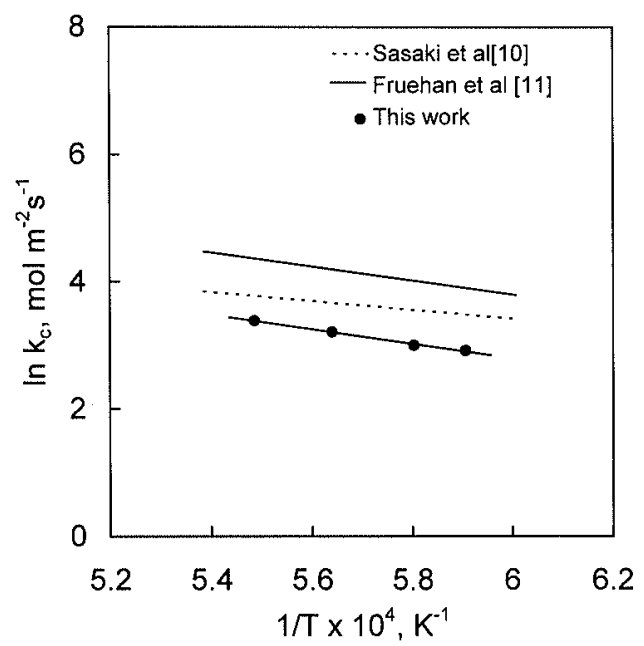

Fig. 8. Effect of temperature on the reaction constant of dissociative chemisorption of $\mathrm{H}_{2} \mathrm{O}$ at the iron melt surface.

chemisorption of $\mathrm{H}_{2} \mathrm{O}$ on the melt surface. The relative resistances of the gas phase mass transport and the interfacial reaction to the overall decarburization can be calculated from the values of $k_{\mathrm{g}}^{\circ}$ and $k_{\mathrm{c}}$ obtained above, and these are 85 and $15 \%$, respectively. Fruehan et al. ${ }^{10)}$ have reported that even with the gas velocity of $13 \mathrm{~m} \mathrm{~s}^{-1}$ they still encountered about $10 \%$ resistance from the gas phase mass transfer.

\subsection{Activation Energies}

In order to elucidate the effect of temperature on the decarburization with $\mathrm{H}_{2} \mathrm{O}$ vapour, experiments were carried out at a number of different temperatures and the results are shown in Fig. 7. It is clear that there is an increase in the rate of decarburization with increasing temperature. Since the gas phase mass transfer coefficients at different temperatures can be obtained using the Steinberger-Treybal equation, Eq. (10), it is possible to calculate the reaction rate constants at the corresponding temperatures using the following relationship:

$$
\frac{1}{k_{\mathrm{app}}}=\frac{1}{k_{\mathrm{g}}^{\circ}}+\frac{1}{k_{\mathrm{c}}}
$$

The results are given in Fig. 8 together with those reported by other investigators. The activation energy of dissociative chemisorption of $\mathrm{H}_{2} \mathrm{O}$ found from the present study is $95 \mathrm{~kJ} \mathrm{~mol}^{-1}$. The activation energies of 58 and $92 \mathrm{~kJ} \mathrm{~mol}^{-1}$ are obtained from the works of Sasaki et al. $^{1{ }^{1)}}$ and of Fruehan et al., ${ }^{10)}$ respectively. These values are in reasonable agreement with each other.

\section{Conclusions}

Decarburization of liquid $\mathrm{Fe}-\mathrm{C}-\mathrm{S}$ drops was investigated using $\mathrm{H}_{2} \mathrm{O}$ vapour by the electromagnetic levitation technique. Findings from this study are summarised in the following:

(1) Decarburization of liquid iron droplets by $\mathrm{H}_{2} \mathrm{O}$ vapour can be adequately described by the mixed control of the gas phase mass transport and the dissociative chemisorption of $\mathrm{H}_{2} \mathrm{O}$ at the melt surface.

(2) The Steinberger-Treybal correlation equation appears to represent the gas phase mass transfer in the present system geometry and experimental conditions.

(3) The rate of decarburization decreases significantly with increase in sulphur content in the melt, and this effect is quantitatively represented by the mixed control model.

(4) There exists a residual rate of decarburization was observed at high sulphur contents in the melt. The extent of the residual rate observed can be interpreted as implying that, even at the melt surface of apparent saturation with sulphur, $9 \%$ of the surface sites are still available for $\mathrm{H}_{2} \mathrm{O}$ molecules to react with carbon.

(5) The activation energy of dissociative chemisorption of $\mathrm{H}_{2} \mathrm{O}$ is $95 \mathrm{~kJ} \mathrm{~mol}^{-1}$.

\section{Acknowledgments}

The authors would like to express their gratitude to the Australian Research Council, CRA-ATD and HIsmelt Corporation Pty. Ltd. for their support to carry out this work.

\section{Nomenclature}

$A:$ interfacial area $\left(\mathrm{m}^{2}\right)$

$\rho_{\mathrm{m}}:$ molar density of metal $\left(\mathrm{mol} \mathrm{m}^{-3}\right)$

$V:$ volume of the sample $\left(\mathrm{m}^{3}\right)$

$k_{\mathrm{g}}$ : gas mass transfer coefficient $\left(\mathrm{m} \mathrm{s}^{-1}\right)$

$v$ : vacant site

$k_{\mathrm{c}}$ : forward rate constant of dissociative chemisorption of $\mathrm{CO}_{2}\left(\mathrm{~mol} \mathrm{~m}^{-2} \mathrm{~s}^{-1}\right)$

$C_{\mathrm{v}}$ : fractional surface site available for $\mathrm{CO}_{2}$ adsorption

$T_{\mathrm{a}}:$ ambient temperature $(\mathrm{K})$

$T_{\mathrm{s}}:$ melt temperature $(\mathrm{K})$

$T_{\mathrm{f}}:$ film temperature $\left(=\left(T_{\mathrm{a}}+T_{\mathrm{s}}\right) / 2\right)(\mathrm{K})$

$T_{\mathrm{c}}:$ critical temperature $(\mathrm{K})$

$P_{\mathrm{c}}$ : critical pressure

$k_{\mathrm{g}}^{\circ}$ : gas mass transfer coefficient $\left(=k_{\mathrm{g}} / R T_{\mathrm{f}}\right)$ $\left(\mathrm{mol} \mathrm{m}^{-2} \mathrm{~s}^{-1}\right)$

Sh: Sherwood number $\left(=k_{\mathrm{g}} d / D\right)$

$\mathrm{Gr}^{\prime}$ : Mean Grashof number $\left(=\mathrm{Gr}_{\mathrm{m}}+(\mathrm{Sc} / \mathrm{Pr})^{0.5} \mathrm{Gr}_{\mathrm{h}}\right)$ 
Sc: Schmidt number $\left(=\mu_{\mathrm{f}} / \rho_{\mathrm{f}} D\right)$

Re: Reynolds number $\left(=\rho_{\mathrm{f}} d v / \mu_{\mathrm{f}}\right)$

$\mathrm{Gr}_{\mathrm{m}}$ : Grashof number for mass transfer $\left(=\rho_{\mathrm{f}} g d^{3}\left(\rho_{\mathrm{i}}-\rho_{\mathrm{b}}\right) / \mu_{\mathrm{f}}^{2}\right)$

$\mathrm{Gr}_{\mathbf{h}}$ : Grashof number for heat transfer $\left(=\rho_{\mathrm{f}}^{2} g d^{3}\left(\rho_{\mathrm{i}}-\rho_{\mathrm{b}}\right) / \mu_{\mathrm{f}}^{2} T_{\mathrm{f}}\right)$

Pr: Prandtl number $\left(=\mu_{\mathrm{f}} C_{\mathrm{p}} / \kappa\right)$

$d$ : diameter of sample $(\mathrm{m})$

$D:$ interdiffusivity in the gas mixture $\left(\mathrm{m}^{2} \mathrm{~s}^{-1}\right)$

$\mu$ : viscosity of gas $\left(\mathrm{kg} \mathrm{m}^{-1} \mathrm{~s}^{-1}\right)$

$\rho:$ density of gas $\left(\mathrm{kg} \mathrm{m}^{-3}\right)$

$v:$ velocity of gas $\left(\mathrm{m} \mathrm{s}^{-1}\right)$

$C_{\mathrm{p}}$ : heat capacity of gas $\left(\mathrm{J} \mathrm{kg}^{-1} \mathrm{~K}^{-1}\right)$

$\kappa:$ thermal conductivity of gas $\left(\mathrm{J} \mathrm{m}^{-1} \mathrm{~s}^{-1} \mathrm{~K}^{-1}\right)$

$g:$ acceleration due to gravity $\left(\mathrm{m} \mathrm{s}^{-2}\right)$

$\theta_{\mathrm{S}}$ : fractional surface sites occupied by sulphur

$\theta_{\mathrm{U}}$ : fractional surface sites not available for sulphur adsorption

$K_{\mathrm{S}}$ : adsorption coefficient of sulphur

$a_{\mathrm{S}}:$ activity of sulphur

$M$ : molecular weight

Superscripts

b: bulk property

i: interfacial property

*: adsorbed state

Subscript

f: film temperature property

\section{REFERENCES}

1) R. J. Fruehan: Proc. Elliot Symp., ed. by P. J. Koros and G. R. St. Pierre, ISS AIME, Warrendale, PA, (1990), 1.
2) G. R. Belton and R. J. Fruehan: Proc. Turkdogan Conf., ISS AIME, Warrendale, PA, (1993).

3) H. W. Gudenau, T. Yang, T. Gemershausen, H. Rosenbaum and K. Wu: Steel. Res., 64 (1993), 372.

4) B. L. Kusack, J. P. Moodie and T. P. Weston: Proc. Mervwyn Willis Sym., U. Melbourne, (1992), 11.1.

5) J. V. Keogh, G. J. Hardie, D. K. Philip and P. D. Burke: AIME 50 Ironmaking Conf., (1990), 635.

6) R. J. Fruehan, G. R. Belton, F. J. Mannion and Y. Sasaki: Metall. Trans. B, 23B (1992), 45.

7) G. R. Belton: Metall. Trans., 24B (1993), 241

8) Y. Shigeno, H. Mitsufuji, M. Tokuda and M. Ohtani: $J$. Jpn. Inst. Met., 47 (1983), 933.

9) P. Distin, G. D. Hallett and F. D. Richardson: J. Iron Steel Inst., August, (1968), 821.

10) R. J. Fruehan and T. Nagasaka: Steelmaking Conf. Proc., ISS-AIME, (1993), 721.

11) Y. Sasaki and G. R. Belton: Trans. Iron Steel Inst. Jpn., 26 (1986), 611.

12) O. Kubachewski: Iron Binary Phase Diagrams, Springer-Verlag, Berlin, (1982)

13) A. Baker, N. A. Warner and A. E. Jenkins: Trans. Metall. Soc. AIME, 239 (1967), 857.

14) D. R. Sain and G. R. Belton: Metall. Trans., 9B (1976), 235.

15) D. R. Sain and G. R. Belton: Metall. Trans., 9B (1978), 403.

16) H. G. Lee and Y. K. Rao: Metall. Trans. B, 13B (1982), 403.

17) H. G. Lee and Y. K. Rao: Metall. Trans. B, 13B (1982), 411.

18) N. J. Simento: PhD Thesis, University of Qld, Australia, (1995).

19) R. L. Steinberger and R. E. Treybal: J. AIChE, 6 (1960), 227.

20) P. W. Atkins: Physical Chemistry, 5th Ed., Oxford University Press, Oxford, (1994), C27.

2I) N. J. Simento, P. C. Hayes and H. G. Lee: To be published.

22) R. B. Bird, W. E. Stewart and E. N. Lightfoot: Transport Phenomena, J. Wiley \& Sons, NY, (1960).

23) R. H. Perry and D. Green: Perry's Chemical Engineers Handbook, McGraw-Hill, New York, (1984), C3. 